\title{
Out-Of-Plane Displacements Determination Based on the Analysis of Point Clouds from TLS Using the M-Split Estimation
}

\author{
Joanna Janicka ${ }^{1}$, Jacek Rapiński ${ }^{1}$, Wioleta Błaszczak-Bąk ${ }^{1}$ and Czesław Suchocki ${ }^{2}$ \\ ${ }^{1}$ University of Warmia and Mazury in Olsztyn, Faculty of Geoengineering, ul. Oczapowskiego 1, \\ 10-719 Olsztyn, Poland, joanna.janicka@uwm.edu.pl, jacek.rapinski@uwm.edu.pl, \\ wioleta.blaszczak@uwm.edu.pl
}

${ }^{2}$ Koszalin University of Technology, Faculty of Civil Engineering Environmental and Geodetic Sciences, ul. Sniadeckich 2, 75-453 Koszalin, Poland

\begin{abstract}
Building structures are exposed to the impact of various forces and natural phenomena. Earthquakes, heavy rains, displacements of land surrounding the building can have a significant and negative impact on the elements of buildings or entire construction objects. Terrestrial laser scanning technology can be successfully used to obtain data on changes in the structure of an object. This papier discusses the use of TLS as a measurement method for obtaining information on displacements and deformations that have occurred after heavy downpour. As a result of the rapid rain, the ground displacement occurred, which in effect led to damage to the retaining wall. The terrestrial laser scanning was used to measure the area covered by the displacements and the M-split method to model the obtained data.
\end{abstract}

Keywords: Buildings, TLS, M-split Estimation, Defects, Hazards.

\section{Introduction}

Laser scanning technology allows to obtain a large amount of information about an object in a short time. For this reason, this technology is becoming increasingly popular also in buildings monitoring. Traditional methods of monitoring work require the involvement of building inspectors who assess the technical condition of the object. They take a series of measurements, drawings and photos and then the collected data are analysed. Sometimes it turns out that some information is missing or the inventory was not carried out correctly. In the classic approach to inventory, deficiencies in documentation require a re-visit to the site of inspection. Terrestrial laser scanning allows you to acquire data as a point cloud of varying accuracy. It is possible to measure an object with a resolution of $1 \mathrm{~mm}$ if such accuracy is required. Each measured point has three coordinates $\mathrm{X}, \mathrm{Y}, \mathrm{Z}$ and the intensity parameter. Thus, very detailed data about the object is obtained, that can be in the next step analyse.

Because some structures of building objects can be represented as vertices, lines, planes or others and can be described by a mathematical function. This gives the opportunity to automate the data processing what was discussed in many publication for example: Janowski and Rapiński (2013), Wang and Hsu (2007) and Zheng (2008). With this assumption it is possible to analyse for e.g. the building wall planarity, edge verticality or vertical and horizontal displacements. In the case of testing the displacement of two elements that constitute two 
planes, the $\mathrm{M}_{\text {split }}$ estimation method can be used. The method developed by prof. Wisniewski (Wiśniewski, 2008), allows to split a functional model into two or more models, and thus identify for example two planes in the cloud of points. This paper presents the possibility of fitting planes into one cloud of points so that it is possible to identify fragments of two concrete slabs of the retaining wall that have been displaced due to ground displacement.

\section{Msplit Estimation Description}

The $\mathrm{M}_{\text {split }}$ estimation method assumes that every measurement result can be a realization of either of two or more different random variables. This estimation method was introduced by Wisniewski (Wiśniewski, 2008) and widely described in (Wiśniweski, 2009) and (Wiśniewski, 2010). Thus, based on the assumption that the functional model is split into two competitive model $Y_{\alpha}$ or $Y_{\beta}$ each observation has its own "split potential" - the possibility to belong to one of the random variables. Therefore, the observation set $\Omega=\left\{y_{i}: i=1,2, \ldots, n\right\}$ is a disordered mixture of the elements assigned to the random variables $y_{\alpha}$ or $y_{\beta}$ in an unknown way. For that reason, each observation $Y_{i}$ may have either of two competitive expected values $E_{\alpha}\left\{Y_{i}\right\}=E\left\{Y_{\alpha}\right\}$ or $E_{\beta}\left\{Y_{i}\right\}=E\left\{Y_{\beta}\right\}$. In this paper the functional model $\mathbf{V}=\mathbf{A X}+\mathbf{L}$ is split into two competitive ones which concern the same vector of observation $\mathbf{L}$ :

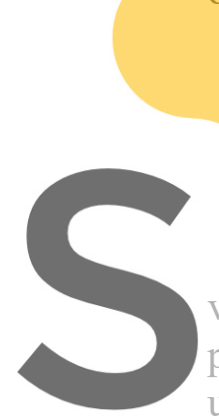

$\operatorname{split}(V=A X+L)=\left\{\begin{array}{l}V_{\alpha}=A X_{\alpha}+L \\ V_{\beta}=A X_{\beta}+L\end{array}\right.$
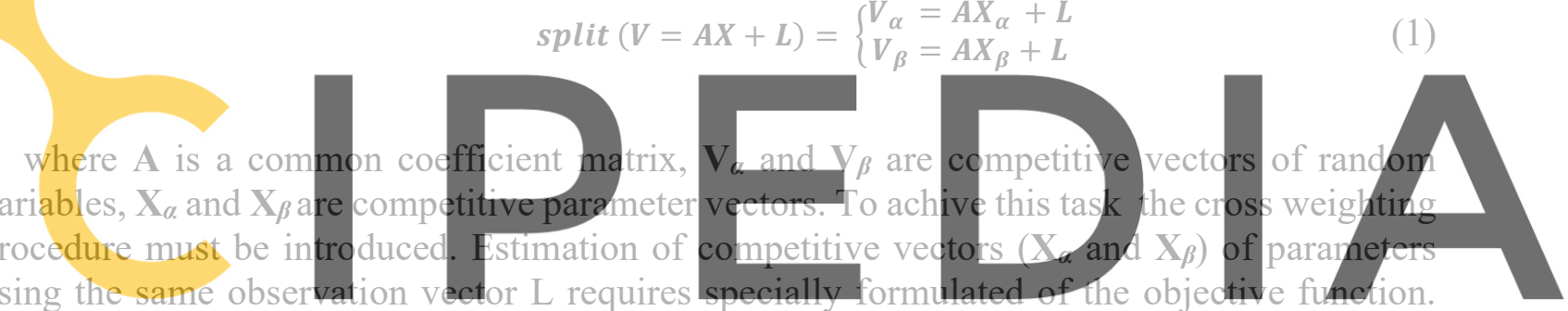

The proposed method replaces function $\rho(v)$ with functions $\rho_{a}\left(v_{a}\right)$ and $\rho_{\beta}\left(v_{\beta}\right)$ according to the

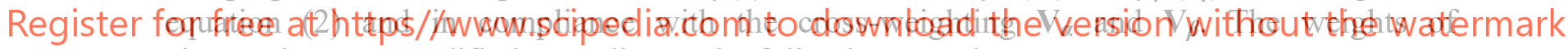
observations are modified according to the following equation:

$$
\begin{aligned}
& \omega_{\alpha}\left(v_{\beta}\right)=\frac{\partial \rho_{\alpha}\left(v_{\alpha}\right)}{\partial\left(v_{\alpha}^{2}\right)} \\
& \omega_{\beta}\left(v_{\alpha}\right)=\frac{\partial \rho_{\beta}\left(v_{\beta}\right)}{\partial\left(v_{\beta}^{2}\right)}
\end{aligned}
$$

If

$$
\rho_{\alpha}\left(v_{\alpha}\right)=v_{\alpha}^{2} v_{\beta}^{2}, \quad \rho_{\beta}\left(v_{\beta}\right)=v_{\beta}^{2} v_{\alpha}^{2}
$$

Then the weight functions can be written in the following form:

$$
\omega_{\alpha}\left(v_{\beta}\right)=v_{\beta}^{2},
$$$$
\omega_{\beta}\left(v_{\alpha}\right)=v_{\alpha}^{2}
$$ 
The idea of $\mathrm{M}_{\text {split }}$ estimation can be easily explained on the example presented in Figure 1.
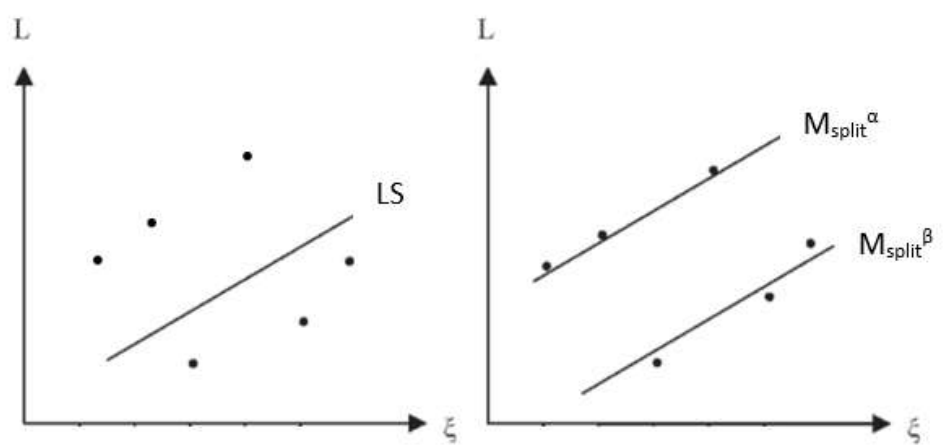

Figure 1. The idea of Msplit estimation and Least Square Method on the example of line fitting.

Figure 1 shows a line fitting using the least squares method and Msplit estimation. Similarly, one can fit two or more planes into a set of points by splitting the functional model into two or more respectively.

\section{Application of $\mathbf{M}_{\text {split }}$ Estimation in Terrestrial Laser Scanning}

Figure 2 shows the selected area of the retaining
of several concrete slabs which as a result of the

formed.
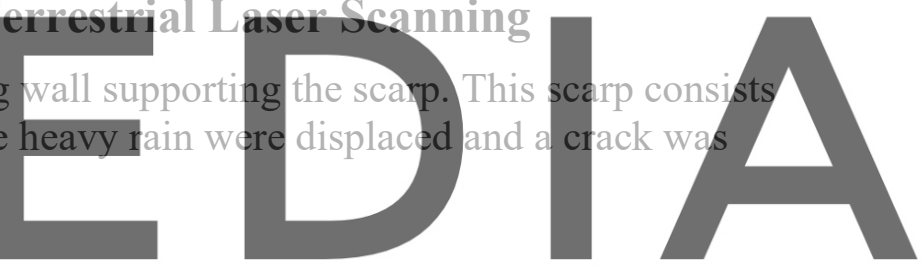

Register for free at https//www.scipedia.com to download the version without the watermark
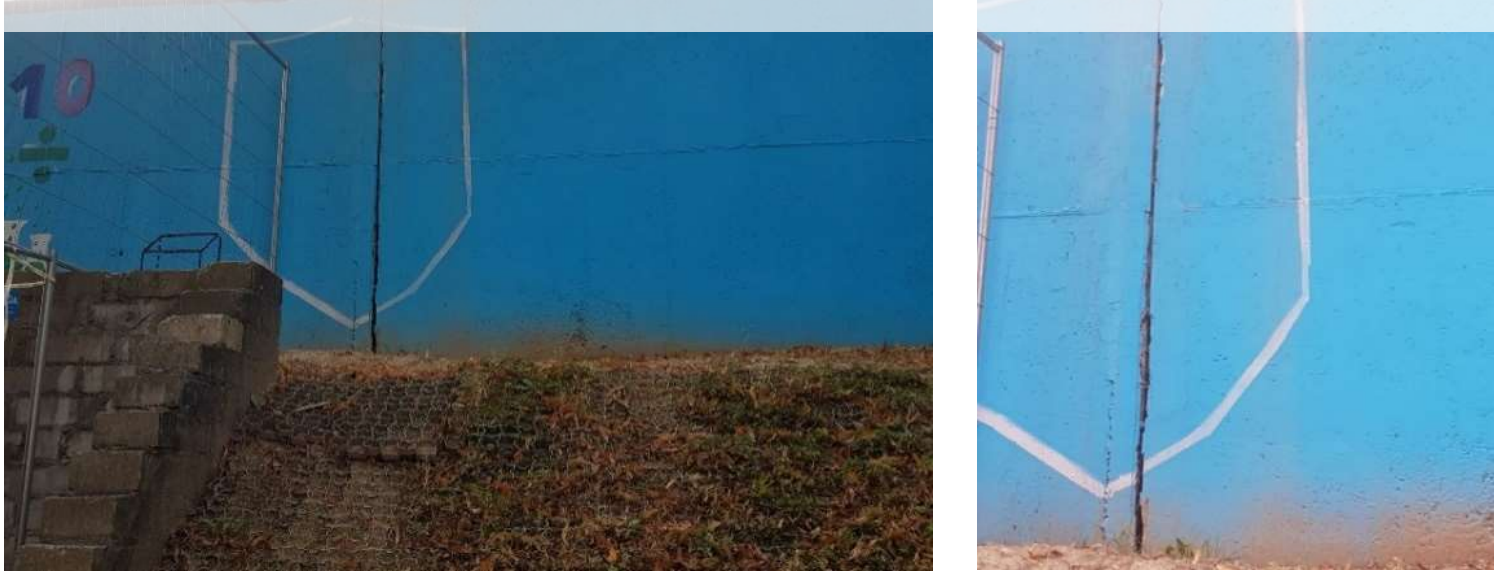

Figure 2. Two concrete slabs displaced due to ground washing. 
The selected fragment shown in Figure 2 was measured using the terrestrial laser scanner. The scanning resolution set to $1 \mathrm{~mm} / 10 \mathrm{~m}$. The crack, that formed as a result of the plates displacement is about 6-7 cm wide. The selected point cloud representing the displaced slabs and a crack is presented in Figure 3.
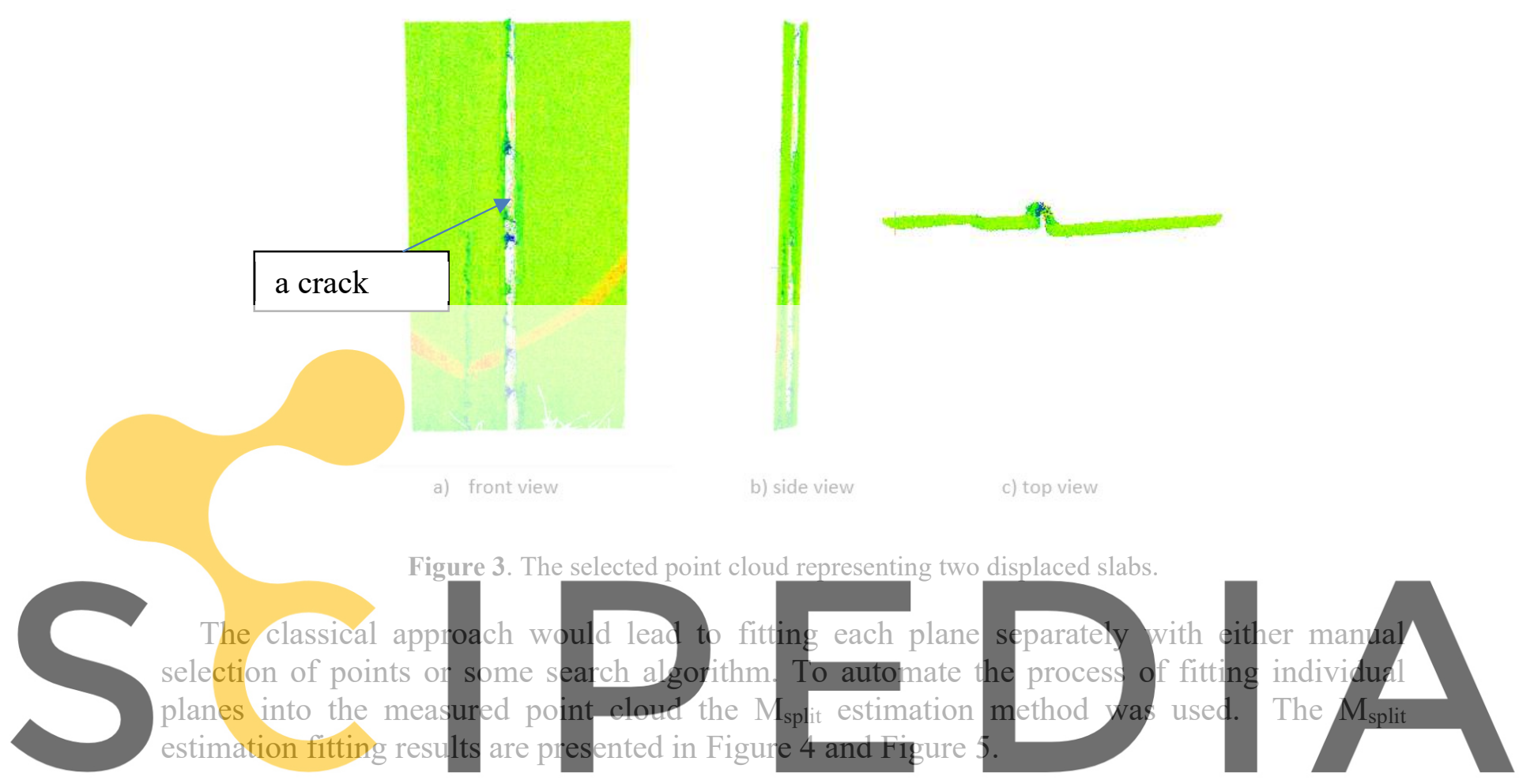

Register for free at https//www.scipedia.com to download the version without the watermark

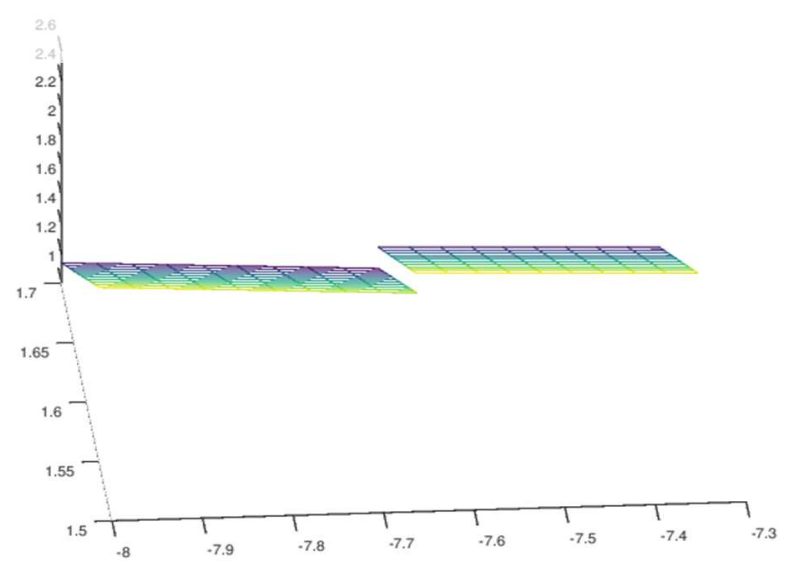

Figure 4. The result of fitting two planes into one cloud of points representing two concrete slabs of a retaining wall. Rotated view. 


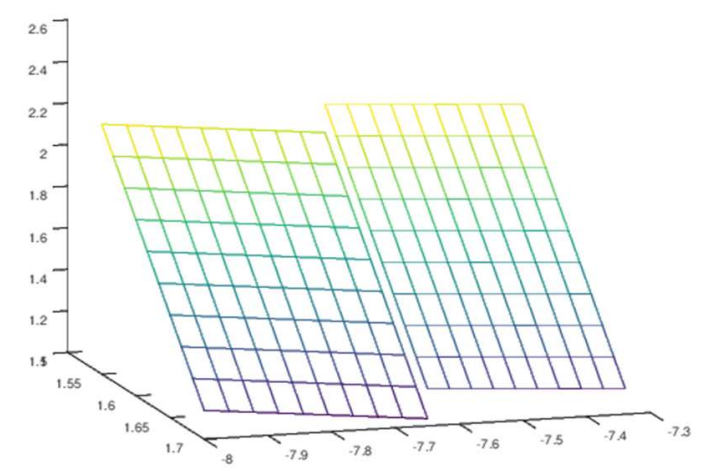

Figure 5. The result of fitting two planes into one cloud of points representing two concrete slabs of a retaining wall. Front view.

Figure 4 and Figure 5 present that the Msplit estimation can be successfully applied in two planes detection. As a result of the proposed algorithm two separate data sets were obtained. Thus, it was possible to automatically fit two planes representing displaced retaining wall slabs.

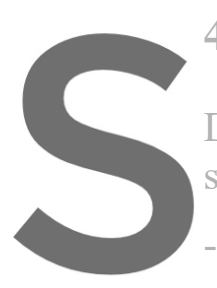

\section{Conclusions}

Displacements deternination

split estimation can be s

The $M_{\text {split }}$ estimation metho
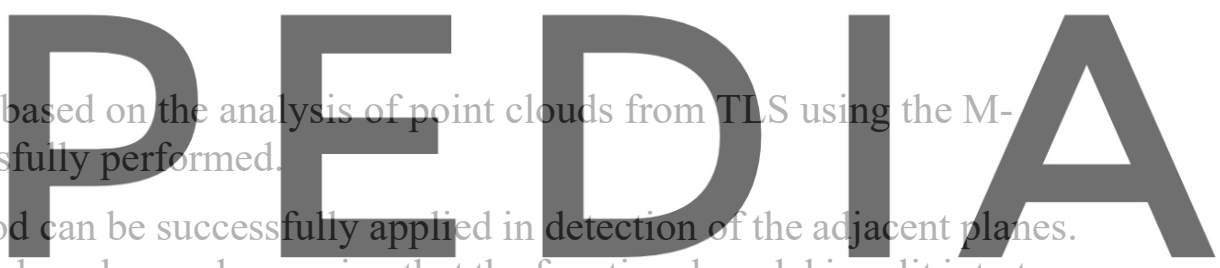

The $\mathrm{M}_{\text {split }}$ estimation method can be used assuming that the funct

Register for free at hustips is possible to fit two planes into one point cloud. displacement of two plates, the distance between them and the angle of their inclination.

The proposed Msplit method has some disadvantages:

- as a result of TLS measuring a huge dataset (point cloud) is obtained, what affects the timeconsuming data processing. So dataset should be reduced using an appropriate algorithm.

- the functional model must be selected very carefully in the terms of mathematical description of estimated model and data structure.

These topics will be the subject to further research and publications

\section{ORCID}

Joanna Janicka:http://orcid.org/ 0000-0002-1504-5354

Jacek Rapiński: http://orcid.org/ 0000-0002-8954-7963

Wioleta Błaczczak-Bąk: http://orcid.org/ 0000-0001-6169-1579

Czesław Suchocki: http://orcid.org/ 0000-0002-0121-5711 


\section{References}

Janicka, J. and Rapinski, J. (2013). Msplit transformation of coordinates. Survey Review, Vol 45, No. 331, 269 274. doi: 10.1179/003962613X13726661625708 .

Wang, C. and Hsu, P. (2007). Building detection and structure line extraction from airborne LiDAR data. Journal of Photogrammetry and Remote Sensing, 12(4), 365- 379.

Wisniewski, Z. (2008). Split estimation of parameters in Functional geodetic models. Technical Sciences, 11, 202-212.

Wisniewski, Z. (2009). Estimation of parameters in A split functional model of geodetic observations (Msplit estimation). Journal of Geodesy, 83, 105-120.

Wisniewski, Z. (2010). Msplit(q) - estimation: Estimation of Parameters in a multi split functional model of geodetic Observations. Journal of Geodesy, 84(6), 355-372.

Zheng, J., McCarthy, T., Fotheringham, A. S. and Yan, L. (2008). Linear feature extraction of buildings from terrestrial LIDAR data with morphological techniques. International Archives of the Photogrammetry Remote Sensing and Spatial Information Science, 37(part B1), 241-244.
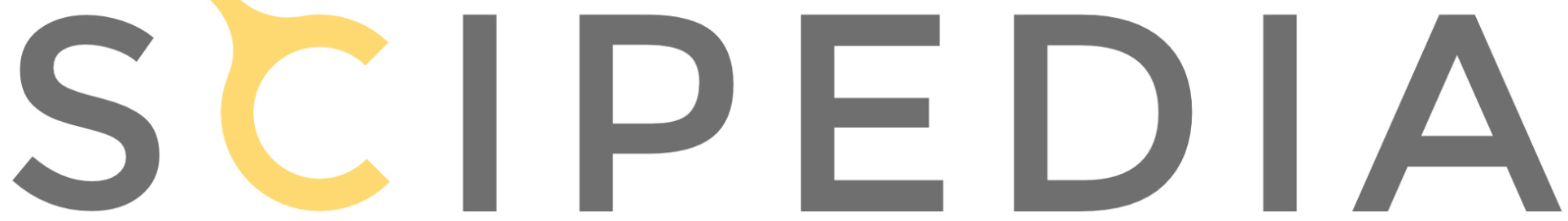

Register for free at https//www.scipedia.com to download the version without the watermark 